\title{
Proposta para análise do design de som em animações educacionais
}

\author{
Proposal for analyses of sound design in educational animation
}

\author{
ALVES, Marcia M.; Doutora em Design; Universidade Federal do Paraná \\ alvesmarcia@gmail.com
}

\begin{abstract}
Resumo
A animação gráfica tem sido estudada por diversas áreas, são comuns artigos sobre sua composição visual, seu conteúdo e discurso. No entanto, quando se fala de animações educacionais esses estudos se tornam mais escassos, principalmente quando abordam o uso do som. No design da informação o som se constitui como canal de equivalente importância para a formação da imagem mental do aprendiz e para o entendimento do conteúdo. Este artigo analisa a aplicação do som em animações e tem como questão de pesquisa: como o canal sonoro é utilizado em animações educacionais? E como objetivo: apresentar um panorama do uso do som em animações educacionais. Para isso, foi gerado um protocolo de análise e coletada uma amostra aleatória e não-probabilística de animações educacionais disponíveis na internet. Como resultado obteve-se uma visão geral do uso do som em animações educacionais e dados que podem fundamentar aperfeiçoamentos na concepção sonora desses materiais.
\end{abstract}

Palavras Chave: animação; educação; design de som.

\begin{abstract}
The graphic animation has been studied by several areas, are common articles on visual composition, content and discourse. However, when talking about educational animations these studies become more scarce, especially when they approach the use of sound. In the design of information, the sound constitutes a channel of equivalent importance for the formation of the mental image in learner and for the understanding the content. This article analyzes the sound of animations and has a question: How the sound channel has been used in educational animations? And as an objective: present a panorama of the use of sound in educational animations. For this, an protocol was generated and a random and non-probabilistic sample was made up of educational animations on the internet. As a result, we obtained an overview of the use of sound in educational animations and data that can base improvements in the sound design of materials.
\end{abstract}

Keywords: animation; education; sound design. 


\section{Introdução}

O avanço tecnológico no campo da comunicação popularizou o uso de dispositivos capazes de abarcar os canais visuais, verbais e sonoros de informação. Os computadores, os televisores, os celulares e os produtos eletrônicos em geral suportam mensagens visuais e sonoras e, por isso, são capazes de transmitir e explorar essas linguagens com facilidade.

Como consequência, o uso desses aparelhos e mídias enquanto recursos educacionais tem sido explorado e ampliado a cada dia. As animações gráficas são um desses recursos que tem adentrado às salas de aula de várias maneiras e, como previa Ainsworth (2008), essas animações com foco educacionais são utilizadas para explicar conceitos, simular fatos, narrar acontecimentos, demonstrar movimentos, apresentar ações e facilitar a compreensão de fatos complexos.

A animação pode ser considerada como uma representação pictórica que apresenta variações (de cor, de posição, de forma ou de movimento) dentro de um determinado período de tempo (LOWE e SCHNOTZ, 2008). A animação pode ser considerada como uma mídia, um material audiovisual, uma linguagem de comunicação (THOMAZ E JOHNSTON, 1995) ou ainda, como uma forma de arte expressiva, reflexiva e crítica (BARBOSA JÚNIOR, 2005).

A animação abriga todos os canais de comunicação pois suporta a linguagem verbal, visual e sonora como todo produto audiovisual. Por isso, ao tomá-la como objeto de estudo deve-se levar em conta esses três canais de comunicação. Esses canais precisam ser configurados de tal forma a atingir o objetivo final desse tipo de animação que é a transmissão da mensagem, no caso educacional, do conteúdo que se quer ensinar/aprender.

Existem várias formas de se conceber e projetar a animação educacional, no entanto, este artigo tem foco na questão sonora da animação. Conforme Vianna (2011) as ações tomadas para o design de um produto ou para a composição visual de um material são semelhantes às ações tomadas para a construção sonora de um material audiovisual. Por isso, ainda conforme o autor mencionado neste parágrafo, considera-se como design de som o projeto e a configuração de elementos sonoros aplicados em um determinado contexto, no caso desta pesquisa, em animações educacionais.

Em revisão sistemática realizada para a tese da autora (ALVES, 2017) no banco de teses e dissertações da CAPES, notou-se pouca quantidade de pesquisas (apenas 8 entre teses e dissertações no período de 2009/2014) com o tema animação e som. Percebeu-se, também que as pesquisas encontradas estavam direcionadas para o estudo da animação enquanto entretenimento e não abordavam a animação educacional.

Ao partir deste contexto este artigo se propõe a iniciar essa pesquisa e a responder a seguinte pergunta: Como o canal do áudio ou o canal sonoro tem sido utilizado em animações educacionais? Essa questão possui o seguinte objetivo: apresentar um panorama do uso do som em animações educacionais para, no futuro, propor possíveis ações futuras para aprimorar essa aplicação.

Portanto, essa pesquisa pode ser considerada exploratória e qualitativa, por buscar uma análise inicial e ainda não numérica ou estatística do fenômeno (MARCONI \& LAKATOS, 1999). Para atingir o objetivo proposto esta pesquisa adotou a técnica de revisão bibliográfica narrativa, a análise sistematizada por meio da confecção de um protocolo e de sua aplicação em uma amostra 
aleatória e não probabilística do universo das animações educacionais presentes na internet.

Este estudo pode ser enquadrado no eixo "Design e Ensino-aprendizagem" do P\&D 2018 e no tópico de "Abordagens tecnológicas" pois tem como objeto de estudo o design de animações educacionais enquanto tecnologia de informação e comunicação (TICs).

Por fim, esse artigo está dividido em: (1) Introdução; (2) A concepção da animação educacional e o design de som; (3) Montagem do instrumento de análise; (4) Resultados e, por fim, (5) Considerações finais.

\section{A concepção da animação educacional e o design de som}

A produção da animação gráfica normalmente está dividida em 4 fases: concepção ou desenvolvimento, pré-produção, produção e pós produção (BARBOSA JÚNIOR, 2005; LAYBOURNE, 1998). Normalmente é na fase inicial em que são tomadas as decisões mais importantes relativas à composição visual e sonora do material. A música e os diálogos são utilizados como guia para a animação e para a divisão das cenas, por isso, são gravados e escolhidos antes da fase de préprodução juntamente com a geração do conceito do material. O som participa de todo o processo, de produção iniciando com os diálogos e encerrando com os últimos efeitos sonoros e possíveis ajustes que podem ser posteriormente aplicados.

Como já mencionado o design da animação envolve a configuração dos três canais de comunicação básicos (verbal, sonoro e visual). No entanto, cada produtor escolhe, ou dá ênfase, à forma de projeto a qual considera mais importante e que conseguirá dar conta dos objetivos do processo e do produto final.

No âmbito do aprendizado um dos estudos que propôs formas e princípios de design para a concepção da animação educacional foi realizado por Richard Mayer (2007). Esse pesquisador e psicólogo propôs a TCAM, Teoria Cognitiva de Aprendizado em Multimídia. Essa teoria foi formulada a partir de vários estudos anteriores sobre o aprendizado e sobre a utilização dos canais de comunicação (e.g. BADDELEY \& HITCH, 1974; BADDELEY, 1999; PAIVIO,1986; SWELLER, 1988; WITTROCK, 1989; MAYER, 1996 in ANDRADE, 2014).

Ainda conforme Mayer (2007, in ALVES, 2012), esses estudos se fundamentam em três princípios básicos do processamento da informação: "(1) as informações visuais e sonoras são processadas em canais diferentes; (2) cada canal possui uma capacidade de processamento limitada por questões individuais de percepção; e, por fim, (3) o processamento da informação nesses ambos canais promove modelos mentais mais próximos da realidade".

Os canais (visual e sonoro) podem ser considerados como básicos, pois o canal verbal pode ser representado por meio visual (quando legenda) ou pelo canal sonoro (quando falas ou diálogos), para a formação da animação. Ao adotar esses princípios a animação passa a lidar com questões de percepção cognitiva e com configurações que permitem a formação de um modelo mental mais completo. Segue uma breve apresentação dos 12 princípios propostos por Mayer (2007): (1) coerência (entre canais, composições visuais e sonoras e na disposição da informação); (2) sinalização (ou ênfases com foco na transmissão da mensagem); (3) redundância (apresentação da mensagem simultaneamente em dois canais diferentes); (4) contiguidade espacial (proximidade entre informações semelhantes); (5) contiguidade temporal (sequências de apresentação); (6) segmentação (partição da informação); (7) pré-treinamento (treinamento 
prévio); (8) modularidade (divisão de conteúdos complexos em módulos); (9) multimídia (uso de diferentes canais); (10) personalização (da informação para o usuário); (11) voz e (12) imagem (adequação da fala e das imagens ao público alvo).

Como pode-se ver os princípios de Mayer abordam a questão da recepção cognitiva da mensagem e exaltam a configuração do som como parte essencial deste processo, ou seja, para a formação completa de um modelo mental se faz necessário a junção do canal visual e sonoro e com isso, tem-se um melhor aprendizado.

Neste contexto, no âmbito do design das animações educacionais existem muitos estudos que focam na questão verbal e narrativa da mensagem com frameworks, esquemas de roteiro, diretrizes e recomendações (e.g. ALVES, BATTAIOLA E CEZAROTTO, 2016). A questão visual também pode ser fundamentada com princípios de design da informação, de ilustração, de estética da animação e de variáveis gráficas (ALVES E BATTAIOLA, 2011). No entanto, o campo do som, dentro dos estudos de design ainda é pouco explorado. No caso educacional, as equipes de produção dessas animações normalmente são pequenas e alguns profissionais como os professores, os autores e os próprios animadores ou designers muitas vezes assumem a produção do som.

Conforme Paraná (2010, p. 49) a música quando acrescentada a animação tem a função de auxiliar a contar a história, a valorizar os pontos mais importantes e situar o espectador quanto ao conteúdo. Conforme Berchmans (2006) a música é capaz de "tocar" o espectador, emocionar, chamar a atenção, imprimir sentimentos e valores às cenas.

Existem várias definições para o design de som, no entanto, para este artigo, considera-se como design de som as atividades de planejamento, manipulação, escolha e geração de todos os sinais sonoros, músicas, diálogos, trilhas e ruídos presentes em um material audiovisual (BERCHMANS, 2006). Realizar o design de som de um material seria projetar as formas de inserção sonora em um projeto. Muitos autores separam da função do designer de som a escolha da música ou trilha sonora e dos diálogos, pois estes podem ser realizados por outros profissionais. Para este trabalho como se deseja analisar as manifestações sonoras de modo geral nas animações educacionais, adotou-se a presença da música e dos diálogos também como uma forma de análise e não foi realizada esta separação desses elemento do design de som.

A fim de definir melhor o trabalho de um designer de som, analisou-se a atuação do designer conforme o texto proposto por Vianna (2011, p. 18):

\footnotetext{
"Neste sentido, a atuação do designer de som é o de configurar os sons escolhidos, manipulando suas qualidades próprias e construindo, assim, a relação som-imagem que será vivenciada pelo espectador através dos dispositivos apropriados para a sua manipulação e apresentação".
}

Atualmente o designer de som tem atuado em diversas áreas, desde o design de produtos até de interfaces, ou seja, em todo o produto ou serviço onde existe a possibilidade da inserção sonora e do uso do canal de áudio se faz necessária a atuação desse profissional. Devido a evolução tecnológica e eletrônica não se tem sons apenas em materiais audiovisuais mas em muitos outros dispositivos, suportes e equipamentos tais como computadores, celulares, games e eletrodomésticos e, ainda, em outros aparatos onde os sons assumem diversas outras funções, tais como os sinais sonoros de advertência aplicados em equipamentos médicos ou, ainda, os sinais que atuam para melhorar a acessibilidade ou o tráfego em vias urbanas (SERAFIN et al., 
2011).

Em uma composição audiovisual o som pode se apresentar de diversas maneiras tais como: diálogos entre personagens, sons do ambiente e do espaço da cena, efeitos sonoros que potencializam ou destacam determinados momentos da mensagem/conteúdo, músicas de fundo e trilhas sonoras. Para efeito de estudos, muitas vezes faz-se um divisão do som em três categorias: música, sound design e diálogos, como já foi relatado, separando a música e os diálogos dos demais sons produzidos em um filme (BERCHMANS, 2006).

Esses sons podem, ou não, serem provenientes das ações e eventos que estão ocorrendo na própria cena, ou seja, os sons podem ser diegéticos (provenientes da própria ação ou evento que ocorre nas cenas, eles podem ser resultados das ações e do ambiente em que a cena está ocorrendo) ou não diegéticos (sons que são inseridos nas cenas de forma externa, como os efeitos especiais, as músicas e trilhas sonoras, que não são provenientes da ação mas auxiliam na transmissão da mensagem) (SONNENSCHEIN, 2001).

Para Stiller (2017) o som é responsável por "suportar" o visual, neste caso, suportar assume o significado de dar suporte ao visual. Para esse autor o som muda a forma do espectador olhar e perceber a imagem, sendo capaz de fornecer informações para o entendimento da cena. $O$ som pode antecipar o que será apresentado no visual e direcionar a atenção do espectador para um ponto importante na cena.

Para Michel Chion (apud SERAFIN et al., 2011) o som pode adquirir duas funções básicas em um filme: informativa (informar os acontecimentos) ou expressiva (qualificar e valorizar os acontecimentos).

Para Sonnenschein (2001) os sons podem ser classificados como:

- Físicos: (mecânicos, técnicos, biológicos) sons típicos do ambiente;

- Emocionais: provenientes de apelos emocionais advindos dos personagens e da dramaturgia para a geração de situações de empatia (risos, choros, gritos);

- Intelectuais: composições estéticas, músicas e textos; e

- Morais: sons que incitam posições éticas e morais (falas, músicas, trilhas) que podem influenciar ao espectador.

Ainda para esse autor, o som compartilha das mesmas figuras de linguagem da literatura verbal ou da composição visual. Por isso, o som pode ser aplicado para estabelecer relações com o visual ao utilizar as seguintes figuras de linguagem:

- Similaridade: similaridade acústica entre dois sons diferentes. Como exemplo, pode-se estabelecer semelhanças entre um grito e uma sirene, para gerar ênfase em uma ação ou, ainda, o humor e o cômico, e, isso pode ser feito no canal sonoro e redundar juntamente com a apresentação visual;

- Hipérbole: consiste em um exagero óbvio e intencional do som, como a inserção de um grito ao invés de um som típico de alarme para um relógio;

- Metáfora: comparação entre sons e ideias que tenham semelhanças ou que combinam, por exemplo, gritos sequenciais estridentes e um pisca-pisca; 
- Alegoria: representação do abstrato pelo concreto, sons complexos para simbolizar pensamentos e memórias;

- Ironia: contraste e oposto, um grito no lugar de uma situação de sorriso;

- Paradoxo: uma contradição muito aparente tais como sons suaves em situações rústicas e agressivas;

- Vivificação: sons resultantes da manifestação de seres inanimados, como o grito advindo de uma porta.

Outra forma de categorizar o som, para esse autor, seria quanto as suas qualidades. Essas qualidades podem ser medidas ou manifestadas pela presença de alguns elementos, tais como:

- Ritmo: qualidade de possuir uma sequência regular ou irregular de notas durante um período de tempo;

- Intensidade: se o som é fraco ou forte, equivale a pressão que a onda sonora exerce no ouvido, pode ser medida em decibéis;

- Tom: se baixo ou alto, medido em hertz;

- Timbre: distinção de sons de mesma frequência e intensidade, podem ser tonal, harmônico ou desordenado;

- Velocidade: tempo de percepção do som, se devagar ou rápido em sua execução;

- Forma: impulsivo ou reverberante se espalhando para o ambiente;

- Organização: ordenado ou caótico.

Fonteles (2014, p. 30 e 31) apresentou em sua dissertação de mestrado uma análise do design de som em ambientes construídos em 3D e como esses espaços construídos influenciam ou são influenciados pelo som. Para isso, ele utilizou uma amostra de animações e elencou algumas categorias de elementos sonoros que podem estar presentes nas cenas:

- Som Ambiente: elementos físicos do espaço da cena. Eles auxiliam no reconhecimento do espaço da cena que pode ser aberto ou fechado sendo que nem todos os sons ambientes precisam ter representação de sua imagem na cena, podem ser, por exemplo, o vento, rios ou seres que estão mais distantes;

- Efeitos: sons "marcantes da composição". Normalmente tem sincronismo com alguma parte visual e podem ser sintetizados (artificiais), ruídos de sala e ruídos específicos (de objetos);

- Músicas: diegéticas ou não-diegéticas e seu estilo;

- Vozes: todas as "expressões vocais dos personagens";

- Sincronia: interação visual/auditiva;

- Ponto de audição: ponto ou posição de onde o espectador escuta o som dos filmes e como ele percebe isso;

- Camadas sonoras: análise do som em camadas divididas pelo seu volume e sua importância na composição; 
- Reverberação do ambiente: características acústicas do ambiente e de seu espaço;

- Paisagem sonora: composição sonora do ambiente da cena;

- Som realista $\mathrm{x}$ ficcional;

- Esterofonia: distribuição do som em canais de transmissão (fones, caixas de som);

- Interação dos efeitos sonoros com as músicas e quando elementos musicais se tornam efeitos. (p. 30 e 31)

Isso posto, nota-se que o designer pode fundamentar a produção e as escolhas realizadas no projeto de som em um material audiovisual de várias formas conforme seus aspectos físicos, emocionais ou técnicos.

Além dessas categorizações relativas a aplicação do sons, tem-se também em educação, recomendações para a produção do som em materiais didáticos tais como as propostas por Souza (2015, p. 59). Esse autor apresenta uma série de funções do som ao ser inserido no material audiovisual em um curso na educação a distância, a primeira vista elas parecem óbvias, e que não necessariamente devem ser realizadas pelo canal sonoro, mas elas trazem conceitos que podem ser inseridos em pontos específicos da animação para melhorar o entendimento do conteúdo:

1. Explicar ao aluno alguma dúvida;

2. Explicar ao aluno algum procedimento para a realização de uma tarefa pedagógica;

3. Exemplificar algum aspecto prático abordado no guia de estudo;

4. Gravar uma seção ou a íntegra do guia de estudo;

5. Apresentar experiências de especialistas sobre uma temática específica.

Neste contexto o som quando direcionado a educação assume um caráter explicativo e uma série de funções que podem limitar suas reais potencialidades para favorecer 0 ato do ensino/aprendizado.

Como pode-se notar cada especialista possui uma forma de categorizar ou analisar o design de som. Para este artigo optou-se por analisar a presença de alguns dos elementos citados e evidenciar uma tendência de uso. Nesse contexto, espera-se com esse artigo, ampliar o estudo do som e verificar o que está sendo realizado atualmente.

\section{Montagem do instrumento de análise}

Mediante as formas de análise propostas pela literatura passou-se para a confeç̧ão do protocolo de análise. Para montagem do instrumento de análise de som das animações educacionais realizou-se uma pesquisa bibliográfica, cujos principais autores e fundamentos foram elencados e descritos no tópico anterior. Após isso, adotou-se o seguinte procedimento:

1. Reunião e análise das propostas dos autores que foram abordados no tópico anterior;

2. Definição da abordagem da análise: devido as possibilidades de diferentes tipos de análises dos sons que foram encontradas na literatura e que poderiam ser realizadas neste trabalho, optou-se por uma análise inicial, com a exploração 13․ Congresso Brasileiro de Pesquisa e Desenvolvimento em Design, Univille, Joinville (SC) 
simples da existência ou não de alguns parâmetros importantes para a construção visual e sonora e importantes para a questão educacional, tais como: tipo de som aplicado, utilização de sons reais ou fictícios, presença de figuras de linguagem, sons diegéticos ou não, a função do som aplicado e como este poderia ser classificado. Essa atitude permitiu reduzir as variáveis e estabelecer o foco na forma da aplicação do som, na presença de alguns elementos e na maneira como esses elementos foram empregados no material. Não foi possível verificar características mais qualitativas como a qualidade do som, a presença de diferentes ritmos e intensidades de som, pois para este tipo de análise mais aprofundada seriam necessários protocolos mais técnicos e a presença de profissionais da área para a certificação do protocolo. Também, não foram propostos confrontos da aplicação do som com as questões pedagógicas pois esses produtos são independentes e apresentados sem um plano pedagógico (disponíveis na internet) e, ainda, são materiais adaptáveis às diferentes realidades de seus usuários/professores, cabendo a esses, realizar as ligações pedagógicas do material com o seu plano de ensino;

3. Seleção das variáveis que continham definição clara e acessível mesmo para não especialistas em música;

4. Montagem de categorias de análise e seleção das variáveis que seriam analisadas em cada categoria.

Depois desses procedimentos montou-se o quadro 1 na página seguinte. 0 quadro apresenta uma estrutura em colunas e tem início com a identificação do material (itens 1 ao 6), daí em diante segue para as categorias de análise levantadas e definidas no tópico anterior. Como já discutido as categorias levantadas analisam a existência ou não de determinados elementos, sendo um protocolo descritivo. Os elementos analisados foram:

1. Tipo de som aplicado: quais sons estão presentes na animação: ambiente, diálogos, música de fundo, efeitos sonoros, trilha sonora, narrador;

2. Veracidade dos sons: os sons utilizados são realistas (advém dos objetos e ações das cenas) ou fictícios (são inseridos após a cena e não são provenientes dos eventos);

3. Quanto a ação nas cenas os sons utilizados são: diegéticos ou não-diegéticos;

4. A função do som na animação: informativo ou expressivo;

5. Existe sincronia sonora/visual: imagem e texto estão sincronizados;

6. Categorias de som: a maioria dos sons da animação podem ser considerados: físicos, intelectuais, emocionais ou morais;

7. Camadas de som: são utilizadas camadas de som, vários níveis de som (para os diálogos, música de fundo, efeitos sonoros e etc.);

8. Esterofonia: o som é distribuído em diferentes canais de transmissão;

9. A integração do som com o visual e a presença de figuras de linguagem: similaridade, hipérbole, metáforas, alegoria, ironia, paradoxo ou vivificação;

10. Som em relação ao visual: O som complementa o visual ou a mensagem está inteiramente no som. 
Quadro 1 - Instrumento de Análise de som em animações educacionais

\begin{tabular}{ll}
\hline Categoria de análise & Variáveis presentes \\
\hline 1. Faixa de ensino & $\begin{array}{l}\text { Educação Infantil/ Ensino Fundamental/ Ensino } \\
\text { Superior/ Ensino especial }\end{array}$ \\
\hline
\end{tabular}

2. Faixa etária

3. Disciplina de destino

4. Ano

5. Empresa Produtora

6. Nacionalidade da Animação

7. Tipo de som aplicado: $\quad$ Ambiente / Diálogos (Falas) / Música de fundo / Efeitos sonoros / Trilha sonora / Narrador

8. Veracidade dos sons, os sons utilizados são: Realistas / Fictícios

9. Os sons utilizados são: Diegéticos / Não-diegéticos

10. Qual é a função do som na animação? Ele é: Informativo / Expressivo

11. Existe sincronia sonora/visual: Sincronizado / Não sincronizado

12. Categorias de som, o som da animação pode ser Físico / Intelectual / Emocional / Moral considerado:

13. Camadas de som: são utilizadas camadas de som? Sim / Não

14. Esterofonia: o som é distribuído em diferentes Sim / Não canais de transmissão?

15. O som/visual apresenta figuras de linguagem?

Não / Sim, quais?

Similaridade / Hipérbole / Metáforas / Alegoria / Ironia /

Paradoxo / Vivificação

16. Som em relação ao visual: o som é:

Complementar / Principal

17. Endereço Eletrônico da Animação

Fonte: adaptado de Sonnenschein (2001); Serafin et al. (2011); Fonteles (2014).

Para escolha da amostra a ser analisada optou-se pela busca de um banco ou biblioteca onde fosse possível conseguir uma quantidade significativa de animações direcionadas ou que tivessem algum fim educacional. Por isso, optou-se por analisar as animações presentes na videoteca do Portal da TV Escola (https://tvescola.org.br/tve/home).

A TV Escola é um canal público de comunicação mantido pelo Ministério da Educação que abriga recursos e materiais educacionais tanto para alunos como para professores. Esse materiais funcionam como apoio ao ensino do aluno e para a capacitação do professor.

O portal abriga todo tipo de recurso. Em sua videoteca tem documentários, animações,

13을 Congresso Brasileiro de Pesquisa e Desenvolvimento em Design, Univille, Joinville (SC)

05 a 08 de novembro de 2018 
séries de animações, vídeo aulas e vídeos educativos. Ao analisar os arquivos da videoteca encontrou-se 28 animações entre séries, curtas e animações mais longas.

No quadro 2 estão presentes os títulos e os endereços das animações analisadas. Todos os vídeos foram vistos na íntegra. No caso das séries, foram assistidos apenas um episódio por título, pois, normalmente as séries mantêm um padrão de aplicação sonora. Depois disso, foi preenchida um planilha do Excel com os resultados encontrados e estes foram analisados por meio de análise de existência e de conteúdo conforme os itens do instrumento de análise.

Quadro 2 - Animações analisadas e localização por meio de endereço eletrônico.

\begin{tabular}{|c|c|}
\hline Animação (curta ou série) & Endereço eletrônico \\
\hline A1:Kiwi (série) & https://tvescola.org.br/tve/video/kiwi-o-lanchinho \\
\hline A2: Dominós & https://tvescola.org.br/tve/video?idltem=11005 \\
\hline A3: A formação das nuvens & https://tvescola.org.br/tve/video?idltem=11118 \\
\hline A4: Hungu & https://tvescola.org.br/tve/video/hungu \\
\hline A5: O poeta dinamarques & https://tvescola.org.br/tve/video?idltem=11174 \\
\hline A6: Maria e eu & https://tvescola.org.br/tve/video/maria-e-eu \\
\hline A7: Do big bang até um dia qualquer & $\begin{array}{l}\text { https://tvescola.org.br/tve/video?vlltem=do-big-bang-ate-um-dia- } \\
\text { qualquer\& }\end{array}$ \\
\hline A8: Se eu fosse Deus & $\begin{array}{l}\text { https://tvescola.org.br/tve/video/especiais-diversos-se-eu-fosse- } \\
\text { deu }\end{array}$ \\
\hline A9: A ciência do bem e do mal & https://tvescola.org.br/tve/video/cienciadobemedomal \\
\hline A10: Morte e vida Severina & https://tvescola.org.br/tve/video/morteevidaseverina \\
\hline A11: Ideias de canário & https://tvescola.org.br/tve/video?idltem=11854 \\
\hline A12: Aurora sem dia & https://tvescola.org.br/tve/video/aurorasemdia \\
\hline A13: Carlos (série) & https://tvescola.org.br/tve/video/carlos-episodios-01-a-05 \\
\hline A14: Contraptus (série) & $\begin{array}{l}\text { https://tvescola.org.br/tve/videoteca- } \\
\text { series!loadSerie?idSerie=14894 }\end{array}$ \\
\hline A15: As chaves de Mardum (série) & $\begin{array}{l}\text { https://tvescola.org.br/tve/video/as-chaves-de-mardum-o- } \\
\text { estranho-comilao }\end{array}$ \\
\hline A16: Mimi e Lisa (série) & https://tvescola.org.br/tve/video?idltem=11112 \\
\hline A17: Mentes Brilhantes (série) & https://tvescola.org.br/tve/video?vlltem=mbleonardodavinci\& \\
\hline A18: Mouk (série) & https://tvescola.org.br/tve/video/mouk-amuleto-da-sorte \\
\hline A19: MOKO (série) & $\begin{array}{l}\text { https://tvescola.org.br/tve/video/moko-o-jovem-explorador-na- } \\
\text { europa-a-terra-branca }\end{array}$ \\
\hline A20: Chico na ilha das jurubebas (série) & $\begin{array}{l}\text { https://tvescola.org.br/tve/video/chico-na-ilha-dos-jurubebas-o- } \\
\text { que-e-o-que-e }\end{array}$ \\
\hline A21: Oto e a música (série) & https://tvescola.org.br/tve/video/oto-e-a-musica-verdi \\
\hline A22: Patos asas e balões & $\begin{array}{l}\text { https://tvescola.org.br/tve/video/patos-asas-e-baloes-1899-a-belle- } \\
\text { epoque }\end{array}$ \\
\hline A23: Punky (série) & https://tvescola.org.br/tve/video?idltem=11104 \\
\hline A24: As aventuras do quati & https://tvescola.org.br/tve/video/as-aventuras-do-quati-mensuria \\
\hline A25: O que são as coisas (série) & https://tvescola.org.br/tve/video?idltem=10999 \\
\hline A26: Defenda-se & https://tvescola.org.br/tve/video/defenda-se-carona \\
\hline $\begin{array}{l}\text { A27: Fabulosas coleções do Seu Gonçalo } \\
\text { (série) }\end{array}$ & https://tvescola.org.br/tve/video?idltem=11147 \\
\hline A28: De onde vem? (série) & $\begin{array}{l}\text { https://tvescola.org.br/tve/video/de-onde-vem-de-onde-vem-a- } \\
\text { televisao }\end{array}$ \\
\hline
\end{tabular}

Fonte: Portal TV Escola (<https://tvescola.org.br/tve/home> Acesso em 5 de abr. de 2018). 
Cada animação foi assistida e classificada conforme o quadro 1. O próximo tópico apresenta os resultados obtidos por meio da análise das animações e algumas discussões que puderam ser realizadas.

\section{Resultados}

Dentre as 28 animações da amostra 15 eram séries de animações e as demais eram curtas ou animações mais longas com tamanhos variáveis. A maioria delas (9) eram indicadas para a Educação Infantil, sendo 8 indicadas para o público geral, 5 para o Ensino Fundamental II, 3 para o nível de alfabetização, duas para o Ensino Fundamental 1 e apenas uma para o Ensino Médio.

A maioria (14) eram indicadas para a faixa etária de 07 a 12 anos, sendo apenas 7 para idades menores que essa faixa e, também 7, para maiores de 13 anos. Os anos de publicações das animações analisadas variam entre 2000 a 2017.

A TV Escola faz uma indicação das disciplinas onde as animações podem ser utilizadas, as mais citadas foram Artes e Ciências, sendo que a maioria poderia ser utilizada em mais de uma disciplina por conter assuntos que são interdisciplinares. As outras disciplinas citadas foram: Língua Inglesa, Sociologia, Artes, Música, Ética, Diversidade, Literatura, História, Biologia, Filosofia, Geografia, Informática, Ciências, Saúde, Matemática, Educação Especial, Química, Física, Meio Ambiente e Língua Portuguesa.

A TV Escola abriga produções nacionais e internacionais, das 28 animações pesquisadas 12 são brasileiras, 8 são canadenses, 4 são francesas e as demais são uma da Eslováquia, uma da Argentina, uma da Itália e uma da Irlanda.

Todos os tipos de sons elencados na fundamentação teórica foram aplicados nas animações. No entanto, os tipos de sons mais presentes nas animações são a Música de fundo e os Efeitos sonoros, presentes em 25 animações. Em 18 delas está presente o som ambiente (sempre presente quando melhora a transmissão da mensagem), em 17 delas estão presentes os diálogos e falas, em 13 estão presentes a trilha sonora e em outras 13 estão presentes narradores.

Todos apresentam sons fictícios e a maioria apresenta sons não-diegéticos, ou seja, elas utilizam sons acrescentados (efeitos sonoros) para complementar as cenas e para auxiliar na transmissão da mensagem, por isso, a maioria tem caráter informativo (21) e 17 delas ainda manifestam funções expressivas (com cargas emocionais e de valores pessoais). Como se tratam de animações educacionais elas possuem um propósito e, por isso, a transmissão da informação é prioridade. No entanto, em muitas animações a função expressiva do som aparece por meio de figuras de linguagem para chamar a atenção acerca de algum conteúdo. As figuras de linguagem que mais apareceram no design do som das animações foram a metáfora, as similaridades, a ironia e o paradoxo. Essas metáforas se manifestam por meio de sons e efeitos sonoros engraçados e exageros na composição sonora associados às imagens.

Em 25 das animações pesquisadas o som aparece sincronizado com a imagem, não sendo apenas um som de fundo. Os sons que mais aparecem são físicos, ou seja, de objetos e de ações presentes na cena. Em segundo lugar tem-se os sons considerados intelectuais com composições musicais e textos. Em 11 produções tem-se músicas com apelos emocionais e 6 delas possuem sons ou falas que ensinam valores morais e estéticos. 
Quanto a quantidade de som na cena ou a presença de camadas sonoras, pode-se notar em 19 produções que existiam músicas de fundo e falas em volumes diferentes que formavam as camadas, onde, na camada mais perceptível ficava o conteúdo, que normalmente eram as falas ou o narrador e nas demais camadas estavam os efeitos sonoros, a música de fundo e demais sons ambientes. Quanto a estereofonia não foi possível perceber essa transmissão em diferentes canais nas animações pesquisadas.

Nas produções analisadas 19 delas tem o conteúdo e a mensagem apresentadas principalmente no som, por meio dos diálogos, músicas ou por intermédio de um narrador. Em 9 animações o som funciona como fator complementar ao que está se passando no canal visual, portanto, visual e verbal precisam ser analisados juntos. Aqui pode-se inferir uma maior tendência quanto a valorização da linguagem verbal por meio do som.

Como pode-se ver existe uma variedade de sons aplicados nas animações educacionais, percebe-se que as séries animadas utilizam mais recursos sonoros e os curtas, muitas vezes, focam na apresentação do conteúdo e, por isso, tem sons reduzidos e focados na transmissão das mensagens. Animações como "Morte e Vida Severina", possuem foco mais na apresentação do poema de João Cabral de Melo Neto, o texto é aplicado nos diálogos dos personagens, tendo poucos efeitos sonoros. Como o foco está no poema, inclusive a questão visual é pautada na apresentação do que o poema está retratando, por isso, são utilizados elementos simples, cenários mais vazios com foco na aridez do sertão, nas falas dos personagens e na representação mais dramática dos fatos. O que também ocorre na animação "Do Big Bang até um dia qualquer" onde se tem uma música clássica que complementa e guia as tensões e imagens que formam a animação, o ritmo das imagens e dos sons combinam em certos momentos e em outros contrastam e criam atmosferas perturbadoras e instigantes, porém, o conteúdo sonoro desta animação é limitado a apenas essa música.

Em "Aurora sem dia" pode-se perceber a utilização de camadas de som e da inserção de ironias e metáforas. Como a animação conta com uma estória e uma narrativa foi possível a inserção de sons fictícios e engraçados em certas situações, em outras são aplicados sons enquanto efeitos sonoros da animação que possuem um caráter mais cômico.

Como já se podia esperar as séries animadas possuem uma maior variedade de sons aplicados com trilhas sonoras, efeitos sonoros, música e cenários que configuram a paisagem sonora da animação. Isso pode ser considerado como resultado do trabalho de equipes maiores e mais tempo dispensado para a produção, o que pode ocasionar aplicações do som mais amplas.

Em uma análise geral pode-se concluir que as animações possuem aplicações variadas de som e que estas aplicações estão ligadas com o seu propósito. Percebe-se, também um discurso explicativo por meio do uso de diálogos e narradores na maioria das animações, pode-se dizer que isso se justificaria devido a função de ensinar que essas animações carregam. Como o foco está no conteúdo, a questão narrativa ou as questões de motivação para a aprendizagem são aplicadas de modo tangencial, utilizadas de forma que possibilitem a melhor transmissão da mensagem.

\section{Considerações Finais}

Este artigo apresentou uma das formas de avaliar o som em animações educacionais e uma análise de 28 animações direcionadas a educação. Com isso, este artigo se posiciona como um 
estudo inicial do som e de seu uso/aplicação em animações educacionais.

Os resultados das análises ainda não foram conclusivos para se formar um panorama, ou gerar recomendações, no entanto, demonstraram algumas tendências e formas com que as animações educacionais utilizam o som. A maioria usa como principal fonte de transmissão da mensagem/conteúdo por meio de diálogos e narradores que se apresentam e atuam de forma explicativa. Porém, o seu uso muitas vezes fica limitado a atender a informação e ao conteúdo educacional e não contribuem em outras funções da animação na educação como forma de motivação para a aprendizagem e, também, não realiza a principal função da música e do canal sonoro, como proposta por Berchmans (2006) no tópico 2 deste artigo que seria de "tocar" o espectador, emocionar, chamar a atenção, imprimir sentimentos e valores às cenas. Em educação os sons normalmente entram como complementares a informação ou tem como prioridade os diálogos que guardam a explanação do conteúdo.

O protocolo construído pode ser ampliado e aplicado em outras situações bem como na concepção das animações educacionais e na sua avaliação. Pode ser utilizado também, por equipes menores de design como forma de sistematização de conhecimento e para conscientizar aos designers acerca das possibilidades de recursos de som que podem ser aplicados em processos de design de animações educacionais. Apesar disso, sabe-se que o uso do protocolo pode ser melhor aplicado por especialistas em produção sonora e que a presença deste profissional na produção de materiais audiovisuais é essencial e enriquecedora ao conteúdo e para toda a produção visual.

Como trabalhos futuros pode-se ampliar essa análise para um número maior de animações para evidenciar um panorama de uso. Pode-se analisar os resultados confrontados com as questões pedagógicas que podem estar envolvidas e gerar recomendações para uma aplicação coerente com a questão pedagógica mas sem esquecer as demais funções motivacionais e emocionais que são características da música e do som. Percebe-se, também, que apesar de os princípios de Mayer (2007) não estarem pontuados no protocolo eles podem ser, também, pontos de avaliação e diretrizes para o design de som, pois pode-se perceber em muitas animações a aplicação dos seus princípios. Pode-se também aplicar esse protocolo no design de animações educacionais em estúdios de animação.

Com isso, espera-se que, ao conhecer as possibilidades de aplicação e os elementos da linguagem sonora, seja possível ampliar as possibilidades projetuais de aplicação do som mesmo para designers não especialistas.

\section{Referências}

ALVES, M. M. Design de animações educacionais: recomendações de conteúdo, apresentação gráfica e motivação para aprendizagem. Dissertação de Mestrado. PPGDesign, Curitiba: UFPR, 2012.

ALVES, M. M. Design de animações educacionais: Modelo para a concepção colaborativa de animações educacionais para o Ensino Fundamental. Tese. PPGDesign, Curitiba: UFPR, 2017.

ALVES, M. M.; BATTAIOLA, A. L.; CEZAROTTO, M. A. Representação gráfica para a inserção de elementos da narrativa na animação educacional. Infodesign (SBDI. Online), v. 13, p. 1-21, 2016. 
ALVES, M. M., BATTAIOLA, A. L. Modelo de análise gráfica para animações educacionais. In: 50 CIDI - Congresso Internacional de Design da Informação e 40 Infodesign. Florianópolis: UFSC, 2011.

ANDRADE, R. de C. Infográficos animados e interativos em saúde: um estudo sobre a compreensão de notícias. Dissertação. Curitiba: UFPR, 2014.

BARBOSA JÚNIOR, A. L. Arte da Animação: técnicas e estética através da História. 2. Ed. Senac: São Paulo, 2005.

BERCHMANS, T. A música do filme: tudo o que você gostaria de saber sobre a música de cinema. 2. Ed. São Paulo: Escrituras Editora, 2006.

CHION, M. Audio-vision: sound on screen. Columbia University Press,1994.

FONTELES, M. G. Da S. A Dimensão Sonora e a Representação do Espaço Imaginário no Cinema de Animação 3D' 27/01/2014 147 f. Mestrado em Comunicação. Universidade de Brasília, 2014.

LAYBOURNE, K. The Animation Book. NY: Three Rivers Press, 1998.

MARCONI, M. A. LAKATOS, E. M. Técnicas de pesquisa. 4. ed. - SP: Atlas, 1999.

MAYER, R. E. Multimedia learning. Second edition. Cambridge University Press: Library of Congress, 2007.

PARANÁ. Secretaria de Estado da Educação. Superintendência da Educação. Diretoria de tecnologias Educacionais. Ilustração digital e animação / Secretaria de Estado da Educação. Superintendência da Educação. Diretoria de tecnologias Educacionais. - Curitiba: SEED - Pr., 2010. - 52 p. - (Cadernos temáticos).

PORTAL TV Escola <https://tvescola.org.br/tve/home> Acesso em 03 de abril de 2018.

SERAFIN, S. et al. Sonic Interaction Design in: Hermann, T., Hunt, A., Neuhoff, J. G., Editors (2011). The Sonification Handbook. Berlin, Germany : Logos Publishing House, 2011.

SONNENSCHEIN, D. Sound Design: the expressive power of music, voice and sound effects in cinema. USA: Michael Wiese Productions, 2001.

SOUZA, R. A. de. Multimídia em educação a distância (versão Cengage). São Paulo: Cengage Learning, 2015.

STILLER, M. Sound Design for Filmmakers: Film School Sound. Paw Print Production, 2017.

THOMAS, F.; JOHNSTON, O. The illusion of life: Disney animation. 1995.

VIANNA, L. E. S. O Design de Som no Cinema: projeto, processo e produção. Dissertação de Mestrado. São Paulo: Anhembi Morumbi, 2011. 